\title{
Dizziness Handicap Inventory and Visual Vertigo Analog Scale in Vestibular Dysfunction
}

\author{
Thaís Alvares de Abreu e Silva Grigol ${ }^{1}$ Adriana Marques Silva ${ }^{1}$ Maristela Mian Ferreira ${ }^{1}$ Andrea Manso ${ }^{1}$ \\ Maurício Malavasi Ganança ${ }^{1}$ Heloisa Helena Caovilla ${ }^{1}$ \\ ${ }^{1}$ Department of Otorhinolaryngology, UNIFESP, São Paulo, \\ São Paulo, Brazil \\ Int Arch Otorhinolaryngol 2016;20:241-243. \\ Address for correspondence Thaís Alvares de Abreu e Silva Grigol, Fga, \\ Department of Otorhinolaryngology, UNIFESP, Rua Pedro de Toledo, \\ 947 São Paulo, São Paulo 04039-032, Brazil \\ (e-mail: thais.grigol@hotmail.com).
}

\begin{abstract}
Introduction Dizziness is one of the most common symptoms among the population, producing numerous consequences for individual's quality of life. There are some questionnaires that can trace the patient's profile and quality of life impairment from dizziness, including the Dizziness Handicap Inventory (DHI) and the Visual Vertigo Analogue Scale (VVAS).

Objective This study aims to correlate the results of the DHI and VVAS in patients with vestibular dysfunction.

Methods This is a retrospective study of medical records of patients treated in a medical school between 2006 and 2012. Results of the DHI and EVA were collected and subjected to statistical analysis using Pearson's correlation test with $p<0.001$. The significance level adopted for the statistical tests was $p \leq 0.05$.

Results A total of 91 records were included in this study, 72 (79.1\%) from female and 19 (20.9\%) from male patients, aged 23 to 86 years, with a mean age of 52.5 years. The

Keywords

- dizziness

- survey

- rehabilitation

- quality of life

- vestibular diseases mean score on the DHI total was 43.9 and 5.2 points for the EVA. The result of Pearson's correlation test was 0.54 .

Conclusion Self-perceived dizziness measured with the Dizziness Handicap Inventory has a regular and positive correlation with the Visual Vertigo Analog Scale in patients with vestibular dysfunction. The clinical trial is registered under number UTN U11111170-5065.
\end{abstract}

\section{Introduction}

Dizziness is one of the most common symptoms among the population, producing numerous consequences for individuals' quality of life. Vestibular testing helps in the diagnosis of vestibular dysfunction, however, it is ineffective in assessing the impact of the symptoms on the daily activities of the patient with dizziness. ${ }^{1}$

There are some questionnaires that can trace the profile and impairment in the quality of life of the patient with dizziness, including the Dizziness Handicap Inventory (DHI), adapted to Brazilian Portuguese and the Visual Vertigo Analogue Scale (VVAS), widely used in clinical

received

July 8,2015

accepted

August 18, 2015

published online

December 14, 2015 practice. ${ }^{2-4}$ These procedures also allow us to analyze the evolution of patients after vestibular rehabilitation intervention. ${ }^{5}$

The DHI is a questionnaire composed of 25 questions, with seven related to physical aspects, nine related to emotional aspects, and nine related to functional aspects. For each question, patients respond "yes," "sometimes," or "no," corresponding to four, two, or zero points, respectively. The maximum score for the physical aspect questions is 28 points and 36 points each for the emotional and functional aspects, totaling a score of 100 points. The higher the score, the worse the impact of dizziness on the quality of life of the patient; the lower the score, the lower the impact. ${ }^{2}$

Copyright $\odot 2016$ by Thieme Publicações License terms Ltda, Rio de Janeiro, Brazil
DOI http://dx.doi.org/ 10.1055/s-0035-1567808. ISSN $1809-9777$.

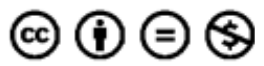


In the VVAS, patients estimate the intensity of their symptoms related to dizziness, vertigo, and imbalance. The scale ranges from zero to ten, zero being the lowest level of dizziness and ten being the greatest. ${ }^{6}$

There is a lack of studies correlating the DHI and the VVAS in the evaluation of the subjective perception of patients with vestibular dysfunction, seeking to measure the impact of dizziness in daily tasks as well as the loss of quality of life. This reason justifies the performance of the current investigation.

The aim of this study was to see whether there is a correlation between the Dizziness Handicap Inventory (DHI) and the Visual Vertigo Analogue Scale (VVAS) in the evaluation of the impact of dizziness on the quality of life of patients with vestibular dysfunction.

\section{Method}

We conducted the study in the Balance sector of the Otology and Neurotology Discipline, Department of Otolaryngology and Head and Neck Surgery Service of the Medical School. It was approved by the Research Ethics Committee (Authorization No. 451.011-08/11/2013).

We analyzed the medical records of patients that responded to the DHI and VVAS between 2006 and 2012. The analysis of the DHI scores classifies the self-perception of dizziness as mild when the score is between zero and 30; moderate, between 31 and 60; and severe, between 61 and 100 . In the VVAS, symptom severity is classified as mild when the score is between zero and three; moderate, between four and six; and severe, between seven and 10 .

We tabulated and analyzed the results statistically. To measure how the variables relate to each other, we applied the Pearson's correlation test, using $\mathrm{p}$ value $<.001$, and adopted an arbitrary classification of percentage for better interpretation of the results, with $0-20 \%$ as the worst; $21-40 \%$ bad; 41-60\% regular; 61-80\% good; and 81-100\% excellent. The significance level adopted was $\mathrm{p} \leq 0.05$.

\section{Results}

We selected a total of 91 medical records; 72 (79.1\%) of the patients were female and 19 (20.9\%) male, aged between 23 and 86 years, with a mean of 52.5 years.

The mean of the DHI total score was 43.9 and 5.2 for the VVAS, both classifying patients' self-perception of impairment caused by dizziness as being of moderate intensity.
- Table 1 shows the results of the DHI and VVAS, according to the classification of mild, moderate and severe. Agreement regarding the level of impairment intensity caused by dizziness occurred in 43 (47.3\%) patients. Of the 48 patients with disagreement regarding the degree of intensity, $60.4 \%$ presented worse scores in the VVAS. Pearson's correlation test found a regular and positive correlation $(r=0.54)$ in the selfperception of symptoms evaluated by the DHI and the VVAS.

\section{Discussion}

In this study, $79.1 \%$ of the participants were female and $20.9 \%$ male. The higher prevalence of vestibular symptoms in females is described in other studies and has a relationship with metabolic, cardiovascular, and hormonal factors. ${ }^{6-10}$ Anxiety and depression, common in females, may also relate to dizziness and may affect the quality of life of such patients. $^{7,9}$

Regarding the age group, prevalence of vestibular symptoms was observed in the 50-60 years age group, as highlighted in other studies. ${ }^{1,6,8,11}$ By the age of 40 , some synaptic changes may already appear in the vestibular nerve, in the 50s, degeneration of the vestibular receptors on the crests of the semicircular canals and saccule may occur, and, in the 60s, increased friction of the nerve fibers of the vestibular nerve and reduction of the conduction velocity of the electrical stimulus in the vestibular nerve may contribute to the onset of dizziness in this age group. ${ }^{12}$

Several studies have used the DHI as a measurement of evolution and have been able to identify improvements in the symptoms of patients when pre- and post-treatment was performed. ${ }^{10,13,14}$ This questionnaire has also proved to be a quick and effective method to detect changes in the quality of life of the patient with vertigo, dizziness, and long-term changes in balance. ${ }^{10,11}$

In the present study, a mean DHI total of 43.9 points was obtained, and the majority of the patients were classified as mild (36.3\%) and moderate (36.2\%), consistent with the findings in the literature. ${ }^{10-15}$ One study, performed with patients between 18 and 60 years of age diagnosed with Meniere's disease, found a mean DHI total between 52 and 57 points, classifying the impairment caused by dizziness as moderate. ${ }^{10}$ In another study, conducted with patients 22 to 76 years of age with cervical lesions, the mean DHI total was 52 points, also classifying the influence of dizziness as moderate. ${ }^{15}$ Similarly, vestibular symptoms and tinnitus

Table 1 Correlation between the findings of the visual vertigo analogue scale and the dizziness handicap inventory

\begin{tabular}{|l|l|l|l|l|}
\hline & DHI - Mild & DHI - Moderate & DHI - Severe & Total \\
\hline VVAS - Mild & $15(16.5 \%)$ & $10(11.0 \%)$ & $01(1.1 \%)$ & $26(28.6 \%)$ \\
\hline VVAS - Moderate & $14(15.4 \%)$ & $12(13.2 \%)$ & $08(8.8 \%)$ & $34(37.4 \%)$ \\
\hline VVAS - Severe & $04(4.4 \%)$ & $11(12.1 \%)$ & $16(17.6 \%)$ & $31(34.1 \%)$ \\
\hline Total & $33(36.3 \%)$ & $33(36.3 \%)$ & $25(27.5 \%)$ & $91(100 \%)$ \\
\hline
\end{tabular}

\footnotetext{
* Pearson's correlation test: $r=0.54$.
} 
were correlated in 27 patients, 17 to 78 years of age, noting that $41.7 \%$ of the cases presented mean points of the DHI in the range considered of mild intensity and $33.3 \%$ in the moderate range. $^{5}$

The VVAS is also commonly used to evaluate patient symptoms, primarily to indicate the evolution of the dizziness condition after vestibular rehabilitation treatment. Regarding the mean of the VVAS, some studies corroborate the findings of the present study, verifying a prevalence of moderate classifications (4-6 points). ${ }^{7,16,17}$ However, in a study with patients with Meniere's disease, the VVAS predominantly produced severe classifications, between 7.17 and 7.81 points, ${ }^{10}$ suggesting that patients selected in this investigation were in the more advanced stages of the disease compared to those of the present study.

The findings of the present study identified a regular positive correlation (54\%) between self-perception of symptoms measured by the DHI and the VVAS. In other words, the higher the DHI score, the higher the score in the VVAS and vice versa.

Despite the regular correlation between the two instruments, we cannot recommend the use of one in place of the other. The VVAS, possibly due to being a more simplistic and subjective measure than the DHI total score, may present a worse score regarding the determination of the intensity of the symptoms. The DHI, given that it is a questionnaire that addresses physical, emotional, and functional aspects of the patient, favoring a more detailed and broader evaluation of the dizziness condition.

Therefore, it is possible to observe that the DHI and the VVAS are measures that help evaluate the disability and impairments that dizziness causes in the daily life of the individual and, taken together, can contribute to better patient management and treatment. Due to the lack of studies, it is important to conduct further research that correlates these instruments to better understand the findings of this study.

\section{Conclusion}

The self-perception of dizziness measured with the DHI has a regular and positive correlation with the visual vertigo analog scale. Both instruments, each with its particularities, allow inference regarding the influence of dizziness on the quality of life of patients with vestibular dysfunction and, together, may contribute to a better comprehension of the clinical condition and assist the evolutionary monitoring of the therapeutic approach.

\section{References}

1 Nishino LK, Granato L, Campos CAH. Aplicação do questionário de qualidade de vida diária em pacientes pré e pós-reabilitação vestibular. Int Arch Otorhinolaryngol 2008;12(4):517-522

2 Jacobson GP, Newman CW. The development of the Dizziness Handicap Inventory. Arch Otolaryngol Head Neck Surg 1990; 116(4):424-427

3 Castro ASO, Gazzola JM, Natour J, Ganança FF. Versão brasileira do Dizziness Handicap Inventory. Pró-Fono Rev Atual Cient. 2007; 19(1):97-104

4 Whitney SL, Wrisley DM, Brown KE, Furman JM. Is perception of handicap related to functional performance in persons with vestibular dysfunction? Otol Neurotol 2004;25(2):139-143

5 Moreira DA, Bohlsen YA, Momensohn-Santos TM, Cherubini AA. Estudo do handicap em pacientes com queixa de tontura, associada ou não ao sintoma zumbido. Int Arch Otorhinolaryngol. 2006;10(4):270-277

6 Morozetti PG, Ganança CF, Chari BM. Comparação de diferentes protocolos de reabilitação vestibular em pacientes com disfunções vestibulares periféricas. J. Soc. Bras. Fonoaudiol. 2011;23(1):44-50

7 Gazzola JM, Ganança FF, Aratani MC, Perracini MR, Ganança MM. Caracterização clínica de idosos com disfunção vestibular crônica. Rev Bras Otorrinolaringol (Engl Ed) 2006;72(4):515-522

8 Verdecchia DH, Mendoza M, Sanguineti F, Binetti AC. Outcomes after vestibular rehabilitation and Wii ${ }^{\circledR}$ therapy in patients with chronic unilateral vestibular hypofunction. Acta Otorrinolaringol Esp 2014;65(6):339-345

9 Kurre A, Straumann D, van Gool CJ, Gloor-Juzi T, Bastiaenen CH. Gender differences in patients with dizziness and unsteadiness regarding self-perceived disability, anxiety, depression, and its associations. BMC Ear Nose Throat Disord 2012;12:2

10 Garcia AP, Ganança MM, Cusin FS, Tomaz A, Ganança FF, Caovilla $\mathrm{HH}$. Reabilitação vestibular com realidade virtual na doença de Ménière. Braz J Otorhinolaryngol. 2013;79(3):366-374

11 Ceballos R, Vargas A. Aplicación y utilidad del Dizziness Handicap Inventory en pacientes con vértigo del Servicio de Otorrinolaringología del Hospital de Especialidades del Centro Médico Nacional Siglo XXI. An Med Assoc Med Hosp ABC. 2004;49:176-183

12 Bittar RSM, Ganança FF. Envelhecimento e tontura. In: Bittar RSM, Ganança FF. Tontura e outras manifestações clínicas. São Paulo: Segmento Farma; 2010:48-52

13 Karapolat H, Celebisoy N, Kirazli Y, et al. Is vestibular rehabilitation as effective in bilateral vestibular dysfunction as in unilateral vestibular dysfunction? Eur J Phys Rehabil Med 2014;50(6):657-663

14 Tamber AL, Wilhelmsen KT, Strand LI. Measurement properties of the Dizziness Handicap Inventory by cross-sectional and longitudinal designs. Health Qual Life Outcomes 2009;7:101

15 Ekvall Hansson E, Månsson NO, Ringsberg KA, Håkansson A. Dizziness among patients with whiplash-associated disorder: a randomized controlled trial. J Rehabil Med 2006;38(6): 387-390

16 Kammerlind AS, Håkansson JK, Skogsberg MC. Effects of balance training in elderly people with nonperipheral vertigo and unsteadiness. Clin Rehabil 2001;15(5):463-470

17 Hansson EE, Månsson NO, Håkansson A. Effects of specific rehabilitation for dizziness among patients in primary health care. A randomized controlled trial. Clin Rehabil 2004;18(5):558-565 